\title{
Clinical comparison of the ProTon and Tono-Pen tonometers with the Goldmann applanation
} tonometer

\author{
Anna Midelfart, Andreas Wigers
}

\begin{abstract}
A clinical evaluation of a new electron ProTon tonometer was performed comparing the values of intraocular pressure (IOP) measured using this instrument with those determined by a similar instrument, Tono-Pen $\mathrm{XL}$, and by Goldmann applanation tonometry. The mean IOP measured in 106 eyes with the ProTon tonometer was not significantly different from that determined with Goldmann applanation, while the IOP values measured with Tono-Pen XL were significantly lower. The $95 \%$ limits of agreement between applanation tonometry and ProTon tonometry were between $-4 \mathrm{~mm}$ $\mathrm{Hg}$ and $5 \mathrm{~mm} \mathrm{Hg}$ and between applanation tonometry and Tono-Pen XL tonometry between $-3 \mathrm{~mm} \mathrm{Hg}$ and $8 \mathrm{~mm} \mathrm{Hg}$. The ProTon tonometer appears to have a higher level of accuracy than the Tono-Pen XL tonometer in clinical practice.

(Brf Ophthalmol 1994; 78: 895-898)
\end{abstract}

In recent years, an automatic microprocessor controlled tonometer, Tono-Pen, has been developed for the measurement of intraocular pressure (IOP). Recently, a new, similar instrument, the ProTon tonometer has been introduced in Norway. The advantage of these small, hand held instruments is that tonometry can be performed more easily and conveniently for both patient and examiner than with classic instruments, such as the Schiøtz tonometer, based on mechanical measurement principles. General practitioners and opticians have begun to use these new tonometers, while for ophthalmologists Goldmann applanation tonometry is still a standard method for determining IOP. However, for some patients - for example, those who do not cooperate with applanation tonometry or who have corneal epithelial irregularities, the new tonometers which come into contact with a very small area of the cornea, may be considered as alternative instruments.

Before these new tonometers can be accepted as adequate alternatives to standard applanation tonometry, their accuracy should be assessed and they should be tested in a routine clinical examination procedure. Until now, several studies have been performed with the Tono-Pen tonometer, but its reliability has not been confirmed. Some investigators have suggested that Tono-Pen measurements of IOP were accurate when compared with Goldmann applanation tonometry, ${ }^{1-5}$ while others have reported significant differences between these two methods ${ }^{6-8}$ or poor reproducibility of measurements. ${ }^{9}$ Several studies have shown that the Tono-Pen has a tendency to overestimate pressures at low IOP levels and underestimate pressures at high IOP levels, ${ }^{6} 7^{10-12}$ or it consistently overestimated the actual IOP in an unpredictable manner. ${ }^{13}$ It was thus found to be difficult to accept this instrument for clinical use.

The purpose of this study was to perform a clinical examination of the new ProTon tonometer using Goldmann applanation tonometry as a standard method. Futhermore, a comparison of the results obtained with the ProTon and Tono-Pen XL tonometers was also performed in order to determine their relative accuracy.

\section{Materials and methods}

The two electronic tonometers ProTon (Tomey Technology, Inc, Cambridge, MA, USA) and Tono-Pen XL (Bio-Rad Inc, Santa Ana, CA, USA) share similar measurement principles, developed on the basis of the Mackay-Marg tonometer. However, their design is different. In both instruments, IOP is converted to an electronic signal which is stored and analysed by a microprocessor. The means of several measurements are given on a digital display, which also shows the range of the single measurements as a measure of reliability. The digital readout minimises user bias. In the ProTon tonometer, the probe and the display unit are separated, while these are located together in the Tono-Pen XL. The Tono-Pen XL stores and averages four accepted measurements, while the ProTon tonometer usually averages three to five. Both instruments emit an audible beep, making the observer aware of the accepted readings. In this study, only the readings with a reliability of $5 \%$ were accepted for Tono-Pen XL and with the highest accuracy (SEM $<0.5 \mathrm{~mm} \mathrm{Hg}$ ) for the ProTon. The IOP was measured according to the instruction manual and both instruments were calibrated daily.

Goldmann applanation tonometry was performed with the applanation tonometer on a Rodenstock slit-lamp. An average systolic diastolic measurement was obtained for each eye. Two measurements were performed on each eye. However, if the difference between the two measurements exceeded $2 \mathrm{~mm} \mathrm{Hg}$, three readings were averaged.

Examination of the patients was performed in a masked fashion. A total of 53 consecutive patients admitted for a routine clinical examination at our department gave their permission to be included in the study. Patients with corneal irregularities were excluded. The refractive error of all of the patients was within $-8.5 \mathrm{D}$ to $+4 \cdot 0 \mathrm{D}$ in both eyes with the exception of three 
Table I Comparison of ProTon, Tono-Pen XL, and Golmann applanation tonometry

\begin{tabular}{|c|c|c|}
\hline & \multicolumn{2}{|l|}{ Mean IOP } \\
\hline & $\begin{array}{l}\text { Right eye }(n=53) \\
(m m H g)(S D)\end{array}$ & $\begin{array}{l}\text { Left eye }(n=53) \\
(m m H g)(S D)\end{array}$ \\
\hline Goldmann & $15 \cdot 9(4 \cdot 1)$ & $15 \cdot 9(4 \cdot 5)$ \\
\hline ProTon & $15 \cdot 4(4 \cdot 2)$ & $15 \cdot 5(5 \cdot 3)$ \\
\hline Tono-Pen XL & $13.3(3.6)$ & $13 \cdot 6(5 \cdot 1)$ \\
\hline
\end{tabular}

Table 2 Agreement between ProTon or Tono-Pen XL tonometers and Goldmann applanation tonometer

\begin{tabular}{|c|c|c|c|c|}
\hline & \multicolumn{4}{|c|}{ Mean IOP } \\
\hline & \multicolumn{2}{|c|}{$\begin{array}{l}\text { Right eye }(n=53) \\
(m m \mathrm{Hg})\end{array}$} & \multicolumn{2}{|c|}{$\begin{array}{l}\text { Left eye }(n=53) \\
(m m H g)\end{array}$} \\
\hline $\begin{array}{l}\text { ProTon: } \\
\text { Mean difference } f \\
\text { Lower limit of agreement } \\
\text { Upper limit of agreement }\end{array}$ & $\begin{array}{r}0 \cdot 4 \\
-4 \cdot 0 \\
4 \cdot 8\end{array}$ & $\begin{array}{l}95 \% \mathrm{CI}^{\star} \\
-0 \cdot 2 \text { to } 1 \cdot 0 \\
-5 \cdot 1 \text { to }-4 \cdot 0 \\
3 \cdot 8 \text { to } 5 \cdot 9\end{array}$ & $\begin{array}{r}0 \cdot 5 \\
-4 \cdot 2 \\
5 \cdot 0\end{array}$ & $\begin{array}{l}95 \% \mathrm{CI}^{\star} \\
-0 \cdot 2 \text { to } 1 \cdot 0 \\
-5 \cdot 3 \text { to }-3 \cdot 1 \\
3.9 \text { to } 6.1\end{array}$ \\
\hline $\begin{array}{l}\text { Tono-Pen XL: } \\
\text { Mean difference } \dagger \\
\text { Lower limit of agreement } \\
\text { Upper limit of agreement }\end{array}$ & $\begin{array}{r}2 \cdot 6 \\
-3 \cdot 0 \\
8 \cdot 2\end{array}$ & $\begin{array}{c}1.7 \text { to } 3.0 \\
-4.4 \text { to }-1.6 \\
6.8 \text { to } 9.5\end{array}$ & $\begin{array}{r}2 \cdot 4 \\
-2 \cdot 5 \\
7 \cdot 1\end{array}$ & $\begin{array}{c}1.8 \text { to } 3.4 \\
-3.6 \text { to }-1.3 \\
5.9 \text { to } 8.3\end{array}$ \\
\hline
\end{tabular}

${ }^{\star}$ Confidence interval. + Goldmann minus ProTon or Tono-Pen XL.

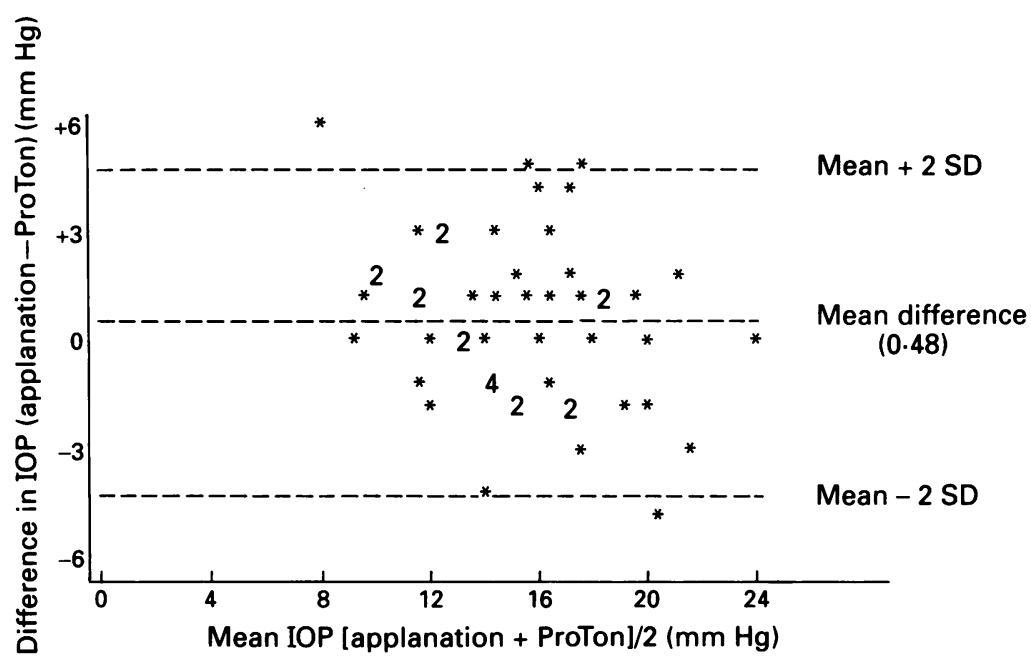

Figure 1 Differences in IOP measured with Goldmann applanation and ProTon tonometry plotted against the mean IOP determined by these two methods in the left eye. Points with overlapping data are denoted as numbers. (95\% limits of agreement.)

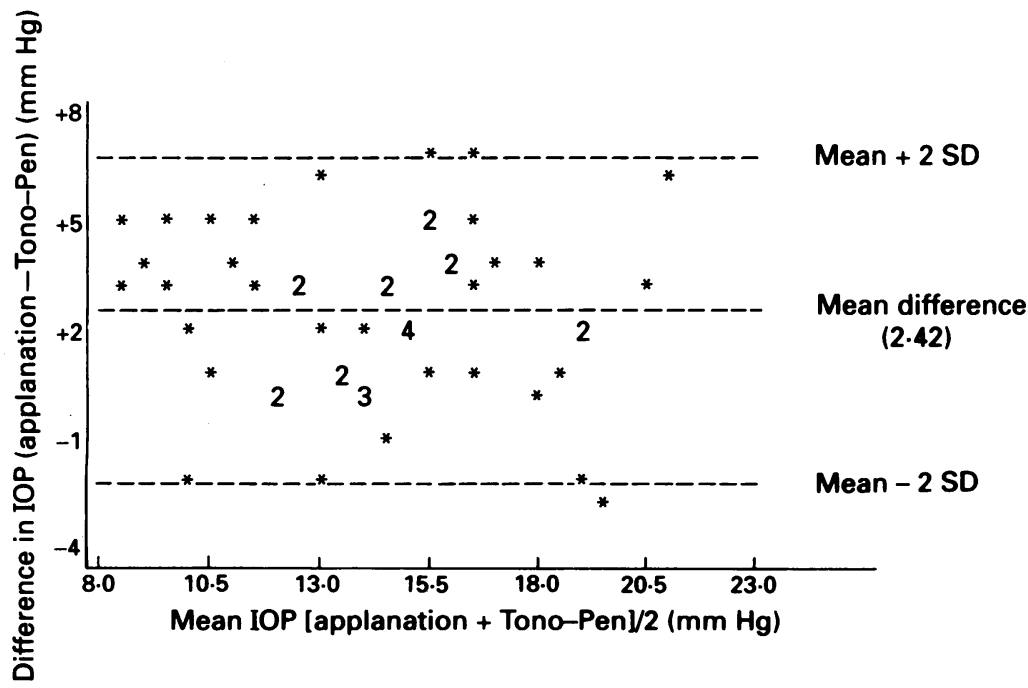

Figure 2 Differences in IOP measured with Goldmann applanation and Tono-Pen XL tonometry plotted against the mean IOP determined by these two methods in the left eye. Points with overlapping data are denoted as numbers. (95\% limits of agreement.) patients with aphakia in the left or right eye. The refractive error of these three eyes was $11.5-13.0 \mathrm{D}$. The astigmatism of one of the aphakic eye was $-4.0 \mathrm{D}$, while astigmatism of all of the other eyes did not exceed $-2 \cdot 0 \mathrm{D}$.

IOP was measured in the right and left eyes of the patients by three investigators (including the author (AW) and two ophthalmic assistants). Three different instruments were used: the Goldmann applanation tonometer, the TonoPen XL tonometer, and the ProTon tonometer. All investigators were trained to use these instruments before the start of the study.

All patients were examined in the same sequence starting with applanation tonometry, followed by ProTon tonometry and Tono-Pen tonometry. The set of readings with these three instruments was obtained within intervals not exceeding 15 minutes.

The results were read into a computer and subjected to statistical analysis. An initial study included all 106 eyes. Separate analyses were then performed for the right and left eyes. Generally, the $t$ test was found appropriate to test the significance of differences between measurements obtained with any two of the instruments. A p value of less than 0.05 was considered statistically significant. A regression analysis was performed to test for irregularities such as heteroscadicity and autocorrelation. As a final check, the Walsh test was used to ascertain whether the readings came from symmetrical populations. The $95 \%$ confidence intervals $(\mathrm{CI})$ and $95 \%$ limits of agreement (mean difference (SD 1.96)) were also calculated according to Bland and Altman. ${ }^{14}$

\section{Results}

The results for IOP measured with the Goldmann applanation tonometer, ProTon tonometer, and Tono-Pen XL tonometer in both eyes of 53 patients are shown in Table 1 . The pressure range of the 106 eyes was $8-38 \mathrm{~mm} \mathrm{Hg}$ with applanation (94 eyes were between $\geqslant 10 \mathrm{~mm} \mathrm{Hg}$ and $\leqslant 20 \mathrm{~mm} \mathrm{Hg}$ ). Statistical analysis revealed a slight deviation from the normal distribution for tonometry data from the right eye with small variations between the three instruments. The left eye readings were very close to a normal distribution for all tonometers. However, there was one outlier in the left eye (IOP $38 \mathrm{~mm} \mathrm{Hg}$ with applanation). As shown by regression analysis, this outlier did not have any noticeable effect on the slope of the regression line and could have safely been included.

Comparing the mean values, the IOP measured with the ProTon tonometer was not significantly different from that determined by applanation tonometry $(p=0 \cdot 166$ in the right eye and $p=0 \cdot 204$ in the left eye). With the Tono-Pen XL, significantly lower values of IOP were measured in comparison with the Goldmann applanation tonometry in both eyes $(\mathrm{p}<0.001)$.

As shown in Table 2, the $95 \%$ limits of agreement between the ProTon tonometer and the applanation tonometer were within $-4 \mathrm{~mm}$ $\mathrm{Hg}$ and $+5 \mathrm{~mm} \mathrm{Hg}$. With Tono-Pen XL the same limits were within $-3 \mathrm{~mm} \mathrm{Hg}$ and $+8 \mathrm{~mm}$ 


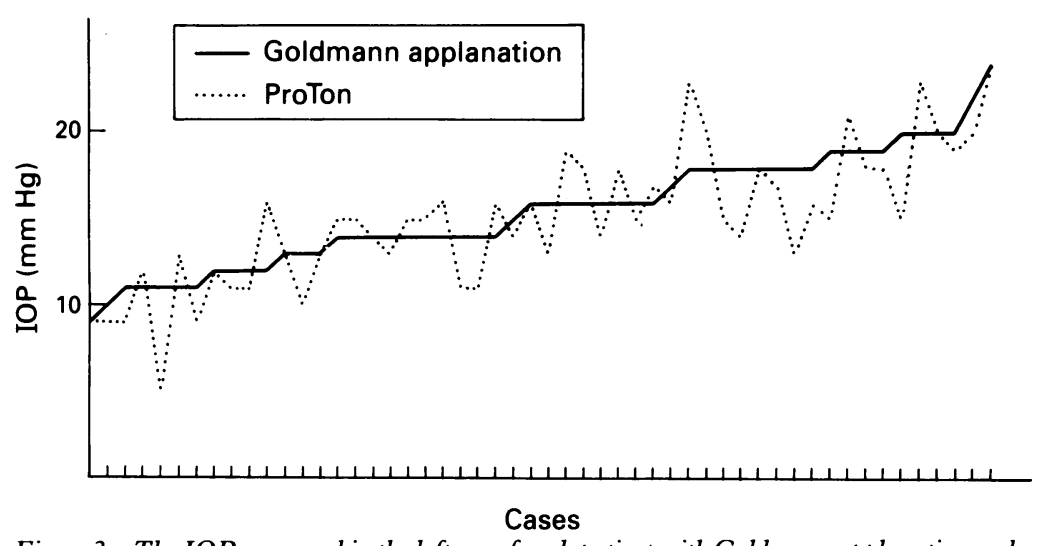

Figure 3 The IOP measured in the left eye of each patient with Goldmann applanation and with ProTon tonometry in relation to the IOP level.

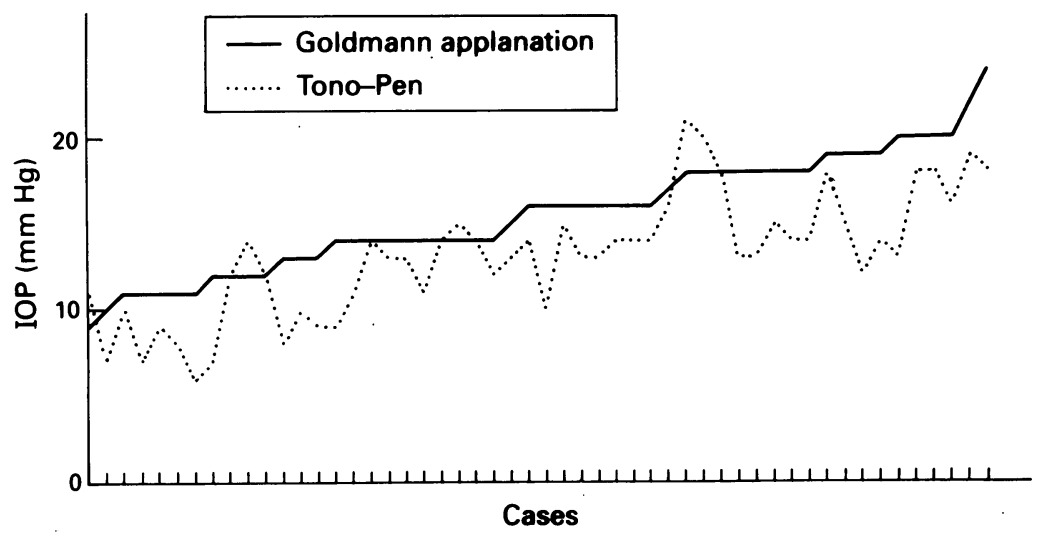

Figure 4 The IOP measured in the left eye of each patient with Goldmann applanation and with Tono-Pen XL tonometry in relation to the IOP level.

$\mathrm{Hg}$, showing a greater variance than the ProTon readings.

Twelve of 106 (11\%) ProTon readings and 39 of $106(37 \%)$ Tono-Pen XL readings differed from the values measured with the Goldmann applanation tonometer by more than $3 \mathrm{~mm} \mathrm{Hg}$. Two of 106 (2\%) ProTon values and 11 of 106 (10\%) Tono-Pen XL values differed by more than $5 \mathrm{~mm} \mathrm{Hg}$.

Analysis of the distribution of differences between Goldmann applanation tonometry and measurements with the ProTon or Tono-Pen XL tonometers revealed that these differences did not vary in any systematic manner over the range of measurements (Figs 1 and 2).

Finally, a check was made for autocorrelation and heteroscadicity in order to find whether one instrument read progressively higher or lower values than the others at different IOP levels. The results show that there was no evidence of autocorrelation when comparing the ProTon or Tono-Pen XL measurements with the applanation tonometry. The same results were obtained when ProTon and Tono-Pen XL readings were subjected to a similar analysis. Comparisons of the measurements made with the applanation tonometry and with ProTon or Tono-Pen XL tonometry in the left eye of each patient are presented in Figures 3 and 4, respectively. The results are sorted according to the IOP level with applanation. As shown in these figures, the readings with ProTon and Tono-Pen XL showed different patterns. With few exceptions, the readings with Tono-Pen XL were below the measurements with applanation tonometry.
The ProTon readings were distributed more symmetrically about the applanation values, indicating a closer correlation between these two instruments.

\section{Discussion}

After the introduction of the new microprocessor controlled tonometers as alternative instruments for measurement of IOP in many countries, it can be expected that these will gradually replace the classic older instruments such as the Schiøtz tonometer. The greatest advantage of the new instruments is the simplicity of their use. Before they can be accepted as equivalent devices to standard tonometers, it is necessary to perform extensive clinical testing and evaluation. Discrepancies in IOP measurements could lead to incorrect clinical decisions - for example, in the detection and treatment of glaucoma.

This is the first clinical study to evaluate the accuracy of the new tonometer ProTon. The results of this study showed a good agreement between the ProTon tonometer and the Goldmann applanation tonometer. The overall accuracy of this instrument was higher than that of the Tono-Pen XL tonometer. In contrast with the Tono-Pen XL, the ProTon tonometer did not show a tendency to underestimate significantly the IOP over the tested IOP range. The limits of agreement between the values obtained with the ProTon and with the Goldmann applanation tonometer in the present study are less wide than those obtained with Tono-Pen XL. For all eyes, $89 \%$ of the ProTon readings and $63 \%$ of the Tono-Pen XL values were within $3 \mathrm{~mm} \mathrm{Hg}$ of the Goldmann applanation. In the clinical studies, a mean error of less than $3 \mathrm{~mm}$ $\mathrm{Hg}$ has been suggested as tolerable in screening situations. ${ }^{8}$

With the Tono-Pen XL, the results obtained in the present study confirmed a statistically significant difference between this tonometer and the Goldmann applanation tonometer reported previously. ${ }^{6-813}$. In this study, a tendency to underestimate the IOP using this instrument in the pressure range $8-38 \mathrm{~mm} \mathrm{Hg}$ with applanation was observed. A possible explanation for that could be a decline of the IOP caused by stress from repeated measurements of IOP using three instruments in each eye. With the applanation tonometer, a decline of the IOP of $2-4.6 \mathrm{~mm} \mathrm{Hg}$ was reported to occur after several repeated readings (for a review see Whiteacre and Stein $\left.{ }^{15}\right)$. Because applanation tonometry was performed first, the possible decline of the IOP as a result of repeated measurements with this instrument will influence all subsequent measurements with the other tonometers in the same manner. Among the other sources of error with the use of the Goldmann applanation tonometer, ${ }^{15}$ the influence of ocular rigidity, corneal irregularity, or astigmatism is of little importance because of the selection of the patients in this study.

How measurement with the ProTon tonometer influences the IOP level is unknown. With the Tono-Pen XL, a possible decline of the IOP after tonometry with this instrument has been reported. ${ }^{4}$ This was explained as a result of 
repeated indentations of the cornea during the measurement. On the other hand, despite using the Tono-Pen uniformly after applanation, a consistent overestimation of the IOP was also observed to occur in both normal and postkeratoplasty eyes. ${ }^{13}$

The results of the present study show that $95 \%$ of the differences between ProTon and Goldmann applanation tonometers were within plus or minus $5 \mathrm{~mm} \mathrm{Hg}$. These limits are relatively wide. Some investigators ${ }^{816}$ have suggested that an average error of more than plus or minus $3 \mathrm{~mm} \mathrm{Hg}$ cannot be tolerated in the diagnosis and treatment of vision threatening diseases when more accurate techniques are available. On the other hand, in complicated cases such as uncooperative patients, where the error rate with any instrument can be expected to be higher than normal, the new tonometers can be considered to be convenient and accurate means of IOP screening. Our findings suggest that the ProTon tonometer represents a better choice than the Tono-Pen XL tonometer, although further investigations with these instruments are still needed to confirm this.

The technical assistance of Mrs Jorid Smiseth and Anne Flønes, ophthalmic assistants at our department, is highly appreciated by the authors. We thank John $G$ Taylor for his assistance in the statistical analysis.

None of the authors has any proprietary or commercial interes in any product or company mentioned.

1 Minckler DS, Baerveldt G, Heuer DK, Quillen-Thomas B, Walonker AF, Weiner J. Clinical evaluation of the Oculab Tono-Pen. Am f Ophthalmol 1987; 104: 168-73.
2 Boothe WA, Lee DA, Panek WC, Pettit TH. The Tono-Pen. Arch Ophthalmol 1988; 106: 1214-7.
Anethe WA, Lee DA, Panek WC, Pet

3 Hines MW, Jost BF, Fogelman KL. Oculab Tono-Pen, Goldmann applanation tonometry, and pneumatic tonometry for intraocular pressure assessment in gas-filled eyes. Am F Ophthalmol 1988; 106: 174-9.

4 Christoffersen T, Fors T, Ringberg U, Holtedahl K. Tonometry in the general practice setting. (I): Tono-Pen com1993; 71: 103-8.

5 Denis $\mathbf{P}$, Nordmann J-P, Bertin V, Gayraud J-M, Laroche L, Saraux $H$. Evaluation of the Tono-Pen 2 and the X-Pert noncontact tonometers in cataract surgery. Ophthalmologica noncontact tonome

6 Kao SF, Lichter PR, Bergstrom TJ, Rowe S, Musch DC. Clinical comparison of the Oculab Tono-Pen to the Goldmann applanation tonometer. Ophthalmology 1987; 94: 1541-4.

7 Farrar SM, Miller KN, Shields MB, Stoup CM. An evaluation of the Tono-Pen for the measurement of diurnal intraocular pressure. Am f Ophthalmol 1989; 107: 411-6.

8 Armstrong TA. Evaluation of the Tono-Pen and the Pulsair tonometers. Am f Ophthalmol 1990; 109: 716-20.

9 Wilson MR, Baker RS, Mohammadi P, Wheeler NC, Lee DA, Scott C. Reproducibility of postural changes in intraocular pressure with the Tono-Pen and Pulsair tonometers. Am $\mathcal{F}$ pressure with the Tono-Pen and

10 Lim JI, Blair NP, Higginbotham EJ, Farber MD, Shaw WE, Garretson BR. Assessment of intraocular pressure in vitrectomized gas-containing eyes. Arch Ophthalmol 1990; 108: 684-8.

11 Hessemer V, Rössler R, Jacobi KW. Comparison of intraocular pressure measurements with the Oculab Tono-Pen vs
manometry in humans shortly after death. Am $\mathcal{f}$ Ophthalmol 1988; 105: 678-82.

12 Moore CG, Milne ST, Morrison JC. Noninvasive measurement of rat intraocular pressure with the Tono-Pen. Invest ment of rat intraocular pressure with

13 Geyer O, Mayron Y, Loewenstein A, Neudorfer M, Rothkoff L, Lazar M. Tono-Pen tonometry in normal and postkeratoplasty eyes. Br f Ophthalmol 1992; 76: 538-40.

14 Bland JM, Altman DG, Statistical methods for assessing agreement between two methods of clinical measurement. Lancet 1986; i: 307-10.

15 Whitacre MM, Stein R. Sources of error with use of Goldmann-type tonometers. Surv Ophthalmol 1993; 38: 1-30.

16 Higginbotham EJ. Clinical evaluation of the Oculab TonoPen. Am f Ophthalmol 1988; 105: 101. 